\title{
Estimativas do Fluxo de Fósforo entre os Compartimentos Anatômicos e Fisiológicos de Suínos Alimentados com Dietas Contendo Diferentes Fontes de Fósforo ${ }^{1}$
}

\section{Alexandre de Oliveira Teixeira ${ }^{2}$, Darci Clementino Lopes ${ }^{3}$, Dorinha Miriam Silber S. Vitti ${ }^{4}$, João Batista Lopes ${ }^{5}$, Paulo Cezar Gomes ${ }^{3}$, José Aparecido Moreira ${ }^{4}$, Sérgio Miranda Pena ${ }^{6}$, Michella de Paschoa Teixeira ${ }^{7}$}

\begin{abstract}
RESUMO - Foram utilizados 21 leitões machos, com peso médio de 31,94 kg, para simulação do fluxo de fósforo (P) entre seus compartimentos anatômicos ou fisiológicos. Utilizou-se o delineamento em blocos casualizados, com sete tratamentos, três repetições e um animal/gaiola. As rações foram à base de milho e de farelo de soja e o P suplementado pelos fosfatos bicálcico (FBC), monobicálcico (MBC), superfosfato triplo (ST), superfosfato simples (SS), rocha catalão (ROCHA) e ácido fosfórico (AcF) e pela ração-controle sem o P suplementar (CONT). No sétimo dia, os animais receberam injeção de 7,4 MBq de $\mathrm{P}^{32}$ e, por sete dias, foram coletadas amostras de fezes, urina e sangue. O P excretado nas fezes foi maior para os suínos que receberam a dieta ROCHA e menor para aqueles que receberam CONT e AcF. O P urinário foi maior os animais dos tratamentos AcF, SS e ST e menor para os do CONT. As dietas não influenciaram a atividade específica (AE) nas fezes e nos ossos. A AE no sangue foi menor para o tratamento ROCHA. A AE nos tecidos moles foi maior nos suínos que receberam CONT e menor para os que que consumiram ST e AcF. O fluxo do P do trato digestivo para a corrente sangüínea foi menor para a dieta CONT, enquanto, para a a dieta contendo ROCHA, houve maior fluxo de P do sangue para o osso. Animais que consumiram ROCHA e CONT reabsorveram mais P do osso. A mobilização dos tecidos moles para a corrente sangüínea foi maior para as dietas ROCHA e CONT. Concluiu-se que a utilização das dietas CONT e ROCHA não forneceu P suficiente para suprir as exigências nutricionais dos suínos, fazendo com que o fluxo do fósforo dos tecidos moles e ossos fosse mais intenso, a fim de manter estável o P na corrente sangüínea. A utilização dos níveis de ácido fosfórico e superfosfato simples nas dietas sobrecarregou os rins, na eliminação do excedente de P pela urina.
\end{abstract}

Palavras-chave: cinética, fosfato, metabolismo, mineral absorção, nutrição, ${ }^{32} \mathrm{P}$

\section{Estimates of Phosphorus Flow between the Anatomical and Physiological Compartments of Swine Fed Diet with Different Sources of Phosphorus}

\begin{abstract}
Twenty-one castrated male pigs with a medium weight of $31.94 \mathrm{~kg}$ were used to simulate the phosphorus (P) flow between its anatomical or physiological compartments. The experiment was arranged in randomized blocks, with seven treatments and four replicates and one pig/box. Corn and soybean meal-based diets were fed and $\mathrm{P}$ was supplied from different phosphate sources: dicalcium (FBC), monodicalcium (MBC), triple superphosphate (ST), simple superphosphate (SS), catalão rock (ROCHA) and phosphoric acid (AcF) and diet control without supplemental P (CONT). At the end of the seventh day, 7.4MBq of ${ }^{32} \mathrm{P}$ were injected in the animals. Samples of feces, urine and blood were collected during seven days. The amount of $\mathrm{P}$ excreted in the feces was greater in the ROCHA diet and smaller in the CONT and AcF diets. Urinary P was greater in the AcF, SS and ST diets and smaller in CONT. The diets did not influence the specific activity (SA) in the feces and in the bones. SA in the blood was smaller in the diet ROCHA. SA in the soft tissues was greater in the diet CONT and smaller in the ST and AcF diets. The flow of $\mathrm{P}$ in the digestive tract for the blood was smaller in the CONT diet. The diet containing ROCHA showed greater flow of $\mathrm{P}$ from the blood to the bone. Animals fed diets ROCHA and CONT reabsorbed more P from the bone. Soft tissue mobilization in the blood was greater in the ROCHA and CONT diets. It was concluded that CONT and ROCHA diet did not supply enough $\mathrm{P}$ to meet swine nutritional requirement, making the phosphorus flow from the soft tissues and bones more intense, in order to maintain a stable $\mathrm{P}$ in the blood. The use of tissues phosphoric acid and simple superphosphate levels in the diets overloaded the kidneys, in the elimination of surplus $\mathrm{P}$ though the urine.
\end{abstract}

Key Words: kinetic, phosphate, metabolism, mineral absorption, nutrition, ${ }^{32} \mathrm{P}$

\footnotetext{
1 Projeto parcialmente financiado pela BUNGE FERTILIZANTES S/A

2 Zootecnista e doutor em Zootecnia - UFV - 36.571-000 - Viçosa - MG (alexandre.teixeira@bunge.com)

3 Professores do Departamento de Zootecnia - UFV - 36.571-000 - Vicosa - MG.

4 Pesquisadores do Departamento de Nutrição Animal - CENA/USP - Piracicaba - SP.

5 Professor do Departamento de Zootecnia - UFPI - Teresina - PI.

${ }^{6}$ Graduando em Zootecnia - UFV - 36.571-000 - Viçosa - MG

${ }^{7}$ Zootecnista, Mestre em Zootecnia - UFV - 36.571-000 - Viçosa - MG
} 


\section{Introdução}

A elaboração de correto manejo nutricional para atender às exigências do organismo requer profundo conhecimento da fisiologia digestiva do suíno, sendo necessário conhecer não somente como funciona o aparelho digestivo, como também a eficiência com que se aproveitam os nutrientes dos alimentos.

$\mathrm{O}$ fósforo de diferentes fontes pode ser absorvido em proporções variadas pelo organismo, graças a uma série de fatores, como espécie e idade do animal, estrutura molecular, processamento das fontes, relação cálcio:fósforo, pH intestinal, níveis dietéticos, presença da vitamina D, gordura, entre outros. É oportuno salientar que nenhum elemento é totalmente absorvido e utilizado pelo animal, pois parte é perdida nos processos normais de digestão e de metabolismo.

$\mathrm{O}$ fósforo $(\mathrm{P})$ disponível e $\mathrm{P}$ digestível não são medidas equivalentes na utilização de fontes $\mathrm{P}$ na formulação de dietas para suínos. Enquanto a disponibilidade de $\mathrm{P}$ é importante para satisfazer às exigências dos suínos, a sua digestibilidade é importante para avaliar a excreção deste mineral, uma vez que, em dietas normais de suínos, em se tratando do fósforo, a excreção fecal, sem dúvida, excede a excreção urinária. Entretanto, Breves \& Schröder (1991) afirmam que a excreção de fósforo pela urina funciona como importante mecanismo de controle homeostático pelos animais monogástricos.

Segundo Furtado (1991), no metabolismo animal, o fósforo mantém estreita relação com o cálcio, durante a absorção, deposição e excreção. Baixa concentração de cálcio sérico estimula a glândula paratireóide do animal a produzir o paratormônio, aumentando, assim, a excreção de fósforo pelos rins, que pode atingir uma taxa 20 vezes superior à da excreção normal. Maior diurese de fosfato mantém constante a relação $\mathrm{Ca}: \mathrm{P}$.

Várias técnicas têm sido usadas para determinação da dinâmica e do metabolismo do fósforo no organismo. A utilização do isótopo radioativo ${ }^{32} \mathrm{P}$ na corrente sangüínea tem como princípio avaliar quantitativamente a absorção real, o metabolismo e o fluxo do fósforo entre o sangue e os vários órgãos e tecidos, bem como a parte excretada nas fezes e na urina (Fernandez, 1995b; Bastianelli et al., 1996; Figueirêdo et al., 1998; Lopes et al., 2001).

A simulação de modelos, principalmente com o uso de traçadores radioativos ou estáveis, permite estudar fenômenos complexos com precisão, dada a possibilidade do acompanhamento das reações e dos mecanismos biológicos ou naturais envolvidos e a quantificação das variáveis, segundo o interesse do pesquisador. Como conseqüência, os resultados da pesquisa, sendo precisos, ao serem extrapolados de forma matemática e estatística para o universo da população, tornam a informação confiável, podendose reduzir o tempo e os gastos com repetição de experimentos com objetivos similares (Lopes, 1999).

Objetivou-se desenvolver modelos para simular o fluxo de $\mathrm{P}$ entre os compartimentos anatômicos ou fisiológicos do organismo de suínos alimentados com dietas contendo diferentes fontes de fósforo.

\section{Material e Métodos}

O experimento foi conduzido no Setor de Suinocultura do Departamento de Zootecnia da Universidade Federal de Viçosa, em Viçosa, Minas Gerais, no período de 19 de outubro a 05 de novembro de 2001.

Foram utilizados 21 leitões machos, castrados, com peso médio de $31,94 \mathrm{~kg}$, distribuídos em delineamento de blocos casualizados, com sete tratamentos e três repetições. O critério adotado para formação dos blocos foram o peso e a idade dos animais.

Os animais foram alojados em gaiolas de estudos metabólicos, estruturadas para separar fezes e urina, com dispositivos para ofornecimentode alimento e de água, semelhantes às descritas por Pekas (1968). Durante o período de adaptação (sete dias) e de coleta total e diária de fezes e de urina e de amostras de sangue (sete dias), um décimo do conteúdo das fezes e da urina foi armazenado em congelador para as devidas análises.

As rações experimentais, exceto a ração-controle, foram formuladas para atender às exigências nutricionais de fósforo dos leitões, conforme recomendações de Rostagno et al. (2000). A composição centesimal e os valores nutricionais das rações experimentais são apresentados na Tabela 1.0 fósforo foi suplementado pelos fosfatos: bicálcico (FBC), monobicálcico (MBC), supertriplo (ST), super simples (SS), rocha catalão (ROCHA) e ácido fosfórico (AcF) e da ração-controle (CONT).

$\mathrm{Na}$ fase de adaptação, as rações experimentais foram fornecidas à vontade em duas refeições (às 10 e $18 \mathrm{~h}$ ), sendo o consumo devidamente registrado. Durante a fase de coleta, as rações experimentais, 
Tabela 1 - Composição das rações experimentais

Table 1 - Composition of the experimental diets

\begin{tabular}{|c|c|c|c|c|c|c|c|}
\hline \multirow{2}{*}{$\begin{array}{l}\text { Ingredientes } \\
\text { Ingredients }\end{array}$} & \multicolumn{7}{|c|}{$\begin{array}{l}\text { Rações experimentais } \\
\text { Experimental diets }\end{array}$} \\
\hline & CONT & FBC & $\mathrm{MBC}$ & ST & SS & $\mathrm{AcF}$ & ROCHA \\
\hline Farelo de soja & 26,30 & 26,30 & 26,30 & 26,30 & 26,30 & 26,30 & 26,30 \\
\hline $\begin{array}{l}\text { Soybean meal } \\
\text { Milho } \\
\text { Corn }\end{array}$ & 68,00 & 68,00 & 68,00 & 68,00 & 68,00 & 68,00 & 68,00 \\
\hline L-lisina & 0,10 & 0,10 & 0,10 & 0,10 & 0,10 & 0,10 & 0,10 \\
\hline $\begin{array}{l}\text { Óleo de soja } \\
\text { Soybean oil }\end{array}$ & 1,65 & 1,65 & 1,65 & 1,65 & 1,65 & 1,65 & 1,65 \\
\hline $\begin{array}{l}\text { Sal } \\
\text { Salt }\end{array}$ & 0,30 & 0,30 & 0,30 & 0,30 & 0,30 & 0,30 & 0,30 \\
\hline $\begin{array}{l}\text { Mistura mineral } \\
\text { Mineral mix }\end{array}$ & 0,05 & 0,05 & 0,05 & 0,05 & 0,05 & 0,05 & 0,05 \\
\hline $\begin{array}{l}\text { Mistura vitamínica }{ }^{2} \\
\text { Vitamin mix }\end{array}$ & 0,10 & 0,10 & 0,10 & 0,10 & 0,10 & 0,10 & 0,10 \\
\hline $\begin{array}{l}\text { Areia lavada } \\
\text { Washed sand }\end{array}$ & 1,78 & 1,23 & 1,15 & 1,06 & 0,00 & 0,70 & 1,62 \\
\hline $\begin{array}{l}\text { Calcário } \\
\text { Limestone }\end{array}$ & 1,72 & 0,99 & 1,17 & 1,28 & 0,36 & 1,78 & 0,00 \\
\hline $\begin{array}{l}\text { Fosfato bicálcico }{ }^{3} \\
\text { Dicalcium phosphate }\end{array}$ & - & 1,28 & - & - & - & - & - \\
\hline $\begin{array}{l}\text { Fosfato monobicálcico } \\
\text { Monodicalcium phosphate }\end{array}$ & - & - & 1,18 & - & - & - & - \\
\hline $\begin{array}{l}\text { Superfosfato triplo } \\
\text { Triple superphosphate }\end{array}$ & - & - & - & 1,160 & - & - & - \\
\hline $\begin{array}{l}\text { Superfosfato simples } \\
\text { Simple superphosphate }\end{array}$ & - & - & - & - & 3,14 & - & - \\
\hline $\begin{array}{l}\text { Ácido fosfórico } \\
\text { Phosphoric acid }\end{array}$ & - & - & - & - & - & 1,02 & - \\
\hline $\begin{array}{l}\text { Fosfato rocha catalão } \\
\text { Phosphate catalão rock } \\
\text { Pos }\end{array}$ & - & - & - & - & - & - & 1,88 \\
\hline Total & 100,00 & 100,00 & 100,00 & 100,00 & 100,00 & 100,00 & 100,00 \\
\hline $\begin{array}{l}\text { Composição calculada }^{4} \\
\text { Calculated composition }^{4}\end{array}$ & & & & & & & \\
\hline $\begin{array}{l}\text { Energia digestível kcal/kg } \\
\text { Digestible energy }\end{array}$ & 3.400 & 3.400 & 3.400 & 3.400 & 3.400 & 3.400 & 3.400 \\
\hline $\begin{array}{l}\text { Proteína }(\%) \\
\text { Crude protein }\end{array}$ & 17,90 & 17,90 & 17,90 & 17,90 & 17,90 & 17,90 & 17,90 \\
\hline $\begin{array}{l}\text { Fósforo total (\%) } \\
\text { Total phosphorus }\end{array}$ & 0,321 & 0,560 & 0,560 & 0,560 & 0,560 & 0,560 & 0,560 \\
\hline $\begin{array}{l}\text { Cálcio }(\%) \\
\text { Calcium }\end{array}$ & 0,780 & 0,780 & 0,780 & 0,780 & 0,780 & 0,780 & 0,780 \\
\hline $\begin{array}{l}\text { Sódio }(\%) \\
\text { Sodium }\end{array}$ & 0,157 & 0,157 & 0,157 & 0,157 & 0,157 & 0,157 & 0,157 \\
\hline $\begin{array}{l}\text { Lisina total }(\%) \\
\text { Total lysine }\end{array}$ & 0,980 & 0,980 & 0,980 & 0,980 & 0,980 & 0,980 & 0,980 \\
\hline $\begin{array}{l}\text { Metionina (\%) } \\
\text { Methionine }\end{array}$ & 0,287 & 0,287 & 0,287 & 0,287 & 0,287 & 0,287 & 0,287 \\
\hline $\begin{array}{l}\text { Met. + cistina }(\%) \\
\text { Methionine + cystine }\end{array}$ & 0,586 & 0,586 & 0,586 & 0,586 & 0,586 & 0,586 & 0,586 \\
\hline $\begin{array}{l}\text { Treonina }(\%) \\
\text { Threonine }\end{array}$ & 0,693 & 0,693 & 0,693 & 0,693 & 0,693 & 0,693 & 0,693 \\
\hline $\begin{array}{l}\text { Triptofano }(\%) \\
\text { Tryptophan }\end{array}$ & 0,212 & 0,212 & 0,212 & 0,212 & 0,212 & 0,212 & 0,212 \\
\hline
\end{tabular}

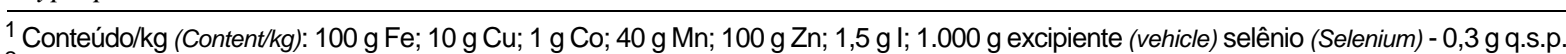

${ }^{2}$ Conteúdo/kg (Content/kg): vit A - 6.000.000 UI; $\mathrm{D}_{3}-1.500 .000 \mathrm{UI} ; \mathrm{E}-15.000 \mathrm{UI} ; \mathrm{B}_{1}-1,35 ; \mathrm{B}_{2}-4 \mathrm{~g} ; \mathrm{B}_{6}-2$ g; ácido pantotênico (Pantothenic acid) - 9,35 g; vit $\mathrm{K}_{3}-1,5 \mathrm{~g}$; ácido nicotínico (Nicotinic acid) - 20,0 g; vit $\mathrm{B}_{12}-20,0 \mathrm{~g}$; ácido fólico (Folic acid) $0,6 \mathrm{~g}$; biotina (Biotin) - $0,08 \mathrm{~g}$; excipiente (vehicle) q.s.p. - $1.000 \mathrm{~g}$.

${ }^{3}$ Análises realizadas no Laboratório de Nutrição Animal do Departamento de Zootecnia da UFV. Conteúdo (\%) de cálcio e fósforo (Ca; P) das fontes: FBC: $(23,25 ; 18,66)$, MBC: $(19,5 ; 20,29), \mathrm{ST}:(16,46 ; 20,63), \mathrm{SS}:(17,2 ; 7,62) ; \mathrm{AcF}:(0,00$; 19,68) e ROCHA: $(36,00 ; 12,73)$.

${ }^{3}$ Analyses were performed at the Laboratory of Animal Nutrition of the Department of Animal Science of UFV: Content (\%) of the calcium and phosphorus (Ca; P) of the source: FBC: (23.25; 18.66), MBC: (19.5; 20.29), ST: (16.46; 20.63), SS: (17.2; 7.62); AcF: (0.00; 19.68) and ROCHA: (36.00; 12.73).

${ }^{4}$ Composição calculada segundo Rostagno et al. (2000) (Calculated composition according to Rostagno et al., 2000). 
também foram distribuídas em duas refeições, porém com o consumo diário com base no peso metabólico $\left(\mathrm{W}^{0,75}\right)$, considerando-se o menor consumo entre os animais de cada bloco observado na fase préexperimental, com água fornecida à vontade.

No início da fase experimental, 7,4 MBq de ${ }^{32} \mathrm{P}$, como fosfato de sódio $\left(\mathrm{Na}_{2} \mathrm{H}^{32} \mathrm{PO}_{4}\right)$ livre de carregador, fornecidos pelo Instituto de Pesquisas Energéticas de São Paulo (IPEN), foram injetados em cada animal, por via endovenosa. Ao final do sétimo dia de aplicação do ${ }^{32} \mathrm{P}$, foram escolhidos 21 leitões de forma casualizada, sendo abatidos três animais por tratamento, e coletadas amostras de osso (10 a a 14a costelas), fígado, coração, rim e músculo (Longissimus dorsi).

A detecção da radioatividade nas amostras de plasma, fezes, urina e dos tecidos foi realizada em espectrômetro de cintilação líquida por efeito Cerenkov (IAEA, 1979). O conteúdo de fósforo inorgânico no plasma foi determinado por colorimetria, segundo Fiske \& Subbarrow (1925), e o dos tecidos, pelo método vanadato-molibdato (Sarruge \& Haag, 1974). As análises foram realizadas no Laboratório de Nutrição Animal do Centro de Energia Nuclear na Agricultura da Universidade de São Paulo.

Os cálculos do percentual das atividades específicas foram feitos de acordo com Salviano \& Vitti (1998).

O modelo proposto do fluxo do fósforo no organismo de leitões encontra-se no esquema simplificado (Figura 1), baseado no fluxo desse mineral (Vitti et al., 2000).

$\mathrm{Na}$ estruturação do modelo foram considerados quatro compartimentos: 1 . trato digestivo, 2. sangue, 3. osso e 4. tecidos moles. O fluxo de fósforo entre os compartimentos, dentro e fora do sistema está caracterizado pelas setas. $\mathrm{O}$ trato digestivo, o osso e os tecidos moles estão em intercâmbio bi-direcional com o pool do sangue, de acordo com o fluxo $\mathrm{F}_{21} \mathrm{e}$ $\mathrm{F}_{12}, \mathrm{~F}_{23}$ e $\mathrm{F}_{32}$ e $\mathrm{F}_{24}$ e $\mathrm{F}_{42}$, respectivamente.

A entrada de fósforo no sistema ocorre via ingestão $\left(\mathrm{F}_{10}\right)$ e a saída por meio das fezes $\left(\mathrm{F}_{01}\right)$ e da urina $\left(\mathrm{F}_{02}\right)$. $\mathrm{O}$ fósforo marcado ${ }^{32} \mathrm{P}$ foi administrado como uma única dose, D cpm, para o tempo "zero", sendo o valor e a atividade específica nos pools sangue, osso e tecidos moles, medidos após oito dias da introdução. Nesse esquema é assumido que não houve reentrada de fósforo marcado a partir de fontes externas.

O princípio da conservação das massas pode ser aplicado em cada pool na Figura 1 para gerar as equações diferenciais, que descrevem o comportamento dinâmico do sistema. Assim, as equações diferenciais de 01 a 04 representam esse princípio para fósforo não-marcado e as equações diferenciais de 05 a 08 para o fósforo marcado, conforme notação definida abaixo.

Os principais símbolos usados no desenvolvimento do modelo são: $\mathrm{F}_{\mathrm{ij}}=$ fluxo total de $\mathrm{P}$ para o pool i a partir do $\mathrm{j}, \mathrm{F}_{\mathrm{i} 0}$ denota fluxo externo dentro do pool $\mathrm{i}$ e $\mathrm{F}_{0 \mathrm{j}}$ o fluxo de saída do sistema a partir do pool j, o sublinhado indica o fluxo que pode ser medido experimentalmente: $\mathrm{g} / \mathrm{d} ; \mathrm{D}=$ dose $\mathrm{de}^{32} \mathrm{P}$ administrada no sangue no tempo zero: $\mathrm{cpm} ; \mathrm{Qi}=$ quantidade total de $\mathrm{P}$ no pool i: g; qi = quantidade de ${ }^{32} \mathrm{P}$ no pool $\mathrm{i}$ : $\mathrm{cpm}$; si = atividade específica do pool i (=qi/Qi): $\mathrm{cpm} / \mathrm{g}$; $\mathrm{T}=$ tempo: $\mathrm{d}$.

$\mathrm{dQ}_{1} / \mathrm{dt}=\mathrm{F}_{10}+\mathrm{F}_{12}-\mathrm{F}_{01}-\mathrm{F}_{21}$

$\mathrm{dQ}_{2} / \mathrm{dt}=\mathrm{F}_{21}+\mathrm{F}_{23}+\mathrm{F}_{02}-\mathrm{F}_{12}-\mathrm{F}_{32}-\mathrm{F}_{42}$

$\mathrm{dQ}_{3} / \mathrm{dt}=\mathrm{F}_{32}-\mathrm{F}_{23}$

$\mathrm{dQ}_{4} / \mathrm{dt}=\mathrm{F}_{42}-\mathrm{F}_{24}$

$\mathrm{dq}_{1} / \mathrm{dt}=\mathrm{s}_{2} \mathrm{~F}_{12}-\mathrm{s}_{1}\left(\mathrm{~F}_{01}+\mathrm{F}_{21}\right)$

$\mathrm{dq}_{2} / \mathrm{dt}=\mathrm{s}_{1} \mathrm{~F}_{21}+\mathrm{s}_{3} \mathrm{~F}_{23}+\mathrm{s}_{4} \mathrm{~F}_{24}-\mathrm{s}_{2}\left(\mathrm{~F}_{02}+\mathrm{F}_{12}+\mathrm{F}_{32}\right.$

$+\mathrm{F}_{42}$ )

$\mathrm{dq}_{3} / \mathrm{dt}=\mathrm{s}_{2} \mathrm{~F}_{32}-\mathrm{s}_{3} \mathrm{~F}_{23}$

$\mathrm{dq}_{4} / \mathrm{dt}=\mathrm{s}_{2} \mathrm{~F}_{42}-\mathrm{s}_{4} \mathrm{~F}_{24}$

Considerando o coeficiente de diferencial de $s_{3}$ com respeito ao tempo, tem-se:

$\mathrm{ds}_{3} / \mathrm{dt}=\mathrm{d}\left(\mathrm{q}_{3} / \mathrm{Q}_{3}\right) / \mathrm{dt}=\left[\mathrm{dq}_{3} / \mathrm{dt}-\left(\mathrm{q}_{3} / \mathrm{Q}_{3}\right) \mathrm{dQ}_{3} / \mathrm{dt}\right] / \mathrm{Q}_{3}$

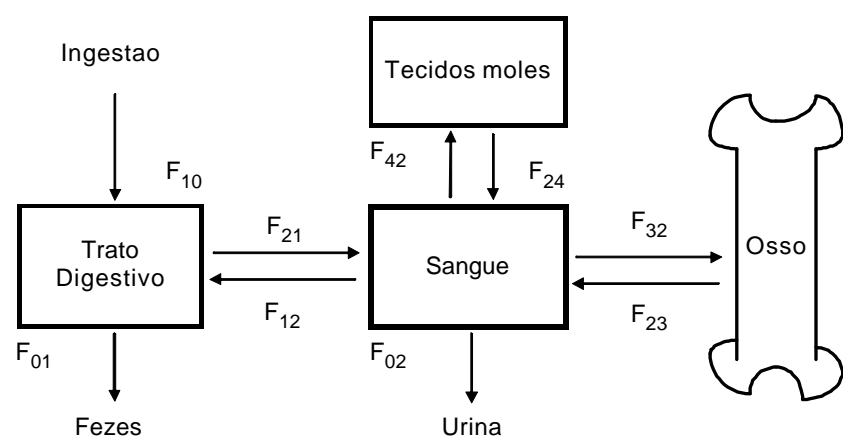

Figura 1 - Esquema do modelo de France, para distribuição de fósforo em suínos.

Figure 1 - Schematic model fo France, for phosphorus distribution in swine.

R. Bras. Zootec., v.33, n.5, p.1246-1253, 2004 
Reorganizando o sistema de equações, obtém-se:

$\mathrm{dq}_{3} / \mathrm{dt}=\mathrm{Q}_{3} \mathrm{ds}_{3} / \mathrm{dt}+\mathrm{s}_{3} \mathrm{dQ}_{3} / \mathrm{dt}$

e, ao utilizar-se as equações (03) e (07) para substituir

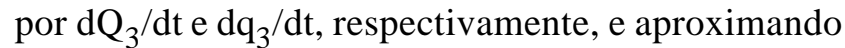
$\mathrm{ds}_{3} / \mathrm{dt}$ por $\left[\mathrm{s}_{3}(\mathrm{t}=\mathrm{t})-\mathrm{s}_{3}(\mathrm{t}=0)\right] /[\mathrm{t}-0]$, a equação $(10)$ torna-se:

$\mathrm{s}_{3} / \mathrm{t}=\left(\mathrm{s}_{2}-\mathrm{s}_{3}\right) \mathrm{F}_{32} / \mathrm{Q}_{3}$

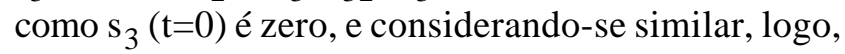
ao aplicar para $\mathrm{ds}_{4} / \mathrm{dt}$, então, tem-se:

$\mathrm{s}_{4} / \mathrm{t}=\left(\mathrm{s}_{2}-\mathrm{s}_{4}\right) \mathrm{F}_{42} / \mathrm{Q}_{4}$

Depois de oito dias de introdução do material radioativo, é assumido que o pool 1 (lumen do intestino) está em estado estável (i.e. ambos dQ1/dt e dq1/dt é zero) e pool 2 (sangue) está em estado não isotópico estável (i.e. dQ2/dt é zero). Assim, as equações (01), (02), (05), (11) e (12) agora se transformam:

$\mathrm{F}_{10}+\mathrm{F}_{12}-\mathrm{F}_{01}-\mathrm{F}_{21} \quad=0$

$\mathrm{F}_{21}+\mathrm{F}_{23}+\mathrm{F}_{02}-\mathrm{F}_{12}-\mathrm{F}_{32}-\mathrm{F}_{42}=0$

$\mathrm{s}_{2} \mathrm{~F}_{12}-\mathrm{s}_{1}\left(\mathrm{~F}_{01}+\mathrm{F}_{21}\right) \quad=0$

$\left(\mathrm{s}_{2}-\mathrm{s}_{3}\right) \mathrm{F}_{32} / \mathrm{Q}_{3}$

$\left(\mathrm{s}_{2}-\mathrm{s}_{4}\right) \mathrm{F}_{42} / \mathrm{Q}_{4}$

$=\mathrm{s}_{3} / 8$

$=\mathrm{s}_{4} / 8$

A partir de manipulação algébrica das equações (13) - (17) resulta:

$\begin{array}{ll}\mathrm{F}_{12} & =\mathrm{s}_{1} \mathrm{~F}_{10} /\left(\mathrm{s}_{2}-\mathrm{s}_{1}\right) \\ \mathrm{F}_{21} & =\mathrm{F}_{10}+\mathrm{F}_{12}-\mathrm{F}_{01} \\ \mathrm{~F}_{32} & =\mathrm{s}_{3} \mathrm{Q}_{3} /\left[8\left(\mathrm{~s}_{2}-\mathrm{s}_{3}\right)\right] \\ \mathrm{F}_{42} & =\mathrm{s}_{4} \mathrm{Q}_{4} /\left[8\left(\mathrm{~s}_{2}-\mathrm{s}_{4}\right)\right] \\ \left|\mathrm{F}_{23}+\mathrm{F}_{24}\right| & =\mathrm{F}_{01}+\mathrm{F}_{12}+\mathrm{F}_{32}+\mathrm{F}_{42}-\mathrm{F}_{21}\end{array}$

em que o $\left|F_{23}+F_{24}\right|$ indica um fluxo experimentalmente medido. O fluxo combinado $\mid \mathrm{F}_{23}$ $+\mathrm{F}_{24} \mid$ denota a soma do fluxo de saída do pool $3 \mathrm{e}$ do pool 4, Equação 23, podendo ser separado pela combinação desses dois pools. O s* denota a atividade específica desse pool combinado, sendo calculado de acordo com a equação 24 .

$$
\begin{aligned}
\left|\mathrm{s}_{23}+\mathrm{F}_{24}\right| & =\mathrm{F}_{23}+\mathrm{F}_{24} \\
& =\left(\mathrm{s}_{3} \mathrm{Q}_{3}+\mathrm{s}_{4} \mathrm{Q}_{4}\right) /\left(\mathrm{Q}_{3}+\mathrm{Q}_{4}\right)
\end{aligned}
$$

O fluxo de saída do marcador a partir do pool combinado é a soma do fluxo de saída do marcador a partir do pool 3 e do pool 4:

$\mathrm{s}^{*} \mathrm{x}\left|\mathrm{F}_{23}+\mathrm{F}_{24}\right|=\mathrm{s}_{3} \mathrm{~F}_{23}+\mathrm{s}_{4} \mathrm{~F}_{24}$

Por meio de manipulação algébrica das equações (23) e (25), obtém-se:

$\mathrm{F}_{24}=\left(\mathrm{s}^{*}-\mathrm{s}_{3}\right) \mathrm{x}\left|\mathrm{F}_{23}+\mathrm{F}_{24}\right| /\left(\mathrm{s}_{4}-\mathrm{s}^{*}\right)$
$\mathrm{F}_{23}=\left|\mathrm{F}_{23}+\mathrm{F}_{24}\right|-\mathrm{F}_{24}$

O modelo é aplicado usando as equações (18) (22), (24) e (26) - (27) para computar os fluxos conhecidos.

A análise estatística dos parâmetros estudados no experimento foi realizada de acordo com o programa Statistical Analysis System (SAS, 1996) e, para comparação das médias entre os tratamentos, utilizou-se o teste Student-Newman-Keuls.

\section{Resultados e Discussão}

Os valores da ingestão, da excreção, das atividades específicas, do conteúdo de fósforo $(\mathrm{P})$ nos ossos, no sangue e nos tecidos moles e o fluxo de entrada e saída de P nos compartimentos, no trato digestivo, no sangue, nos ossos e nos tecidos moles, em função das dietas experimentais, são apresentados na Tabela 2.

$\mathrm{O}$ fósforo consumido foi influenciado $(\mathrm{P}<0,05)$ pelos níveis de $\mathrm{P}$ da dieta, pois, como previsto, os animais que receberam a dieta CONT, que possuía menor nível de fósforo total, consumiram menos P. O consumo deste mineral foi similar para os tratamentos que continham fontes inorgânicas de $\mathrm{P}$ suplementar.

Verificou-se que o nível de $\mathrm{P}$ excretado nas fezes foi maior $(\mathrm{P}<0,05)$ nos animais que consumiram a dieta suplementada com fosfato de rocha, sendo similar $(\mathrm{P}>0,05)$ nos animais tratados com ST, MBC e FBC. A maior excreção foi observada nos animais dos tratamentos CONT e AcF, que foram semelhantes $(\mathrm{P}>0,05)$ às dietas $\mathrm{FBC}$ e SS.

A excreção de $\mathrm{P}$ pela urina foi maior $(\mathrm{P}<0,05)$ para os tratamentos com AcF, SS e ST, seguidos por FBC, MBC e ROCHA. A menor excreção de P via urina ocorreu no CONT, que foi semelhante $(\mathrm{P}>0,05)$ aos tratamentos MBC e ROCHA.

As dietas experimentais não influenciaram $(\mathrm{P}>0,05)$ a atividade específica (AE) nas fezes (S1) e nos ossos (S3) dos suínos. A AE no sangue (S2) foi menor $(\mathrm{P}<0,05)$ para o tratamento com fosfato de rocha como fonte suplementar, não havendo diferença $(\mathrm{P}>0,05)$ entre os demais tratamentos. Entretanto, a $\mathrm{AE}$ nos tecidos moles foi maior $(\mathrm{P}<0,05)$ nos animais que consumiram a dieta CONT, sendo similar $(\mathrm{P}>0,05)$ à $\mathrm{AE}$ daqueles que receberam $\mathrm{FBC}, \mathrm{SS}, \mathrm{ROCHA} \mathrm{e}$ MBC. A menor AE foi observada nos animais que consumiram as dietas $\mathrm{ST}$ e AcF, que foram semelhantes $(\mathrm{P}>0,05)$ às dietas $\mathrm{FBC}, \mathrm{SS}, \mathrm{ROCHA}$ e MBC.

$\mathrm{O}$ fluxo de entrada de $\mathrm{P}$ no trato digestivo pela corrente sangüínea $\left(\mathrm{F}_{12}\right)$ não foi influenciado $(\mathrm{P}>0,05)$ 
TEIXEIRA et al.

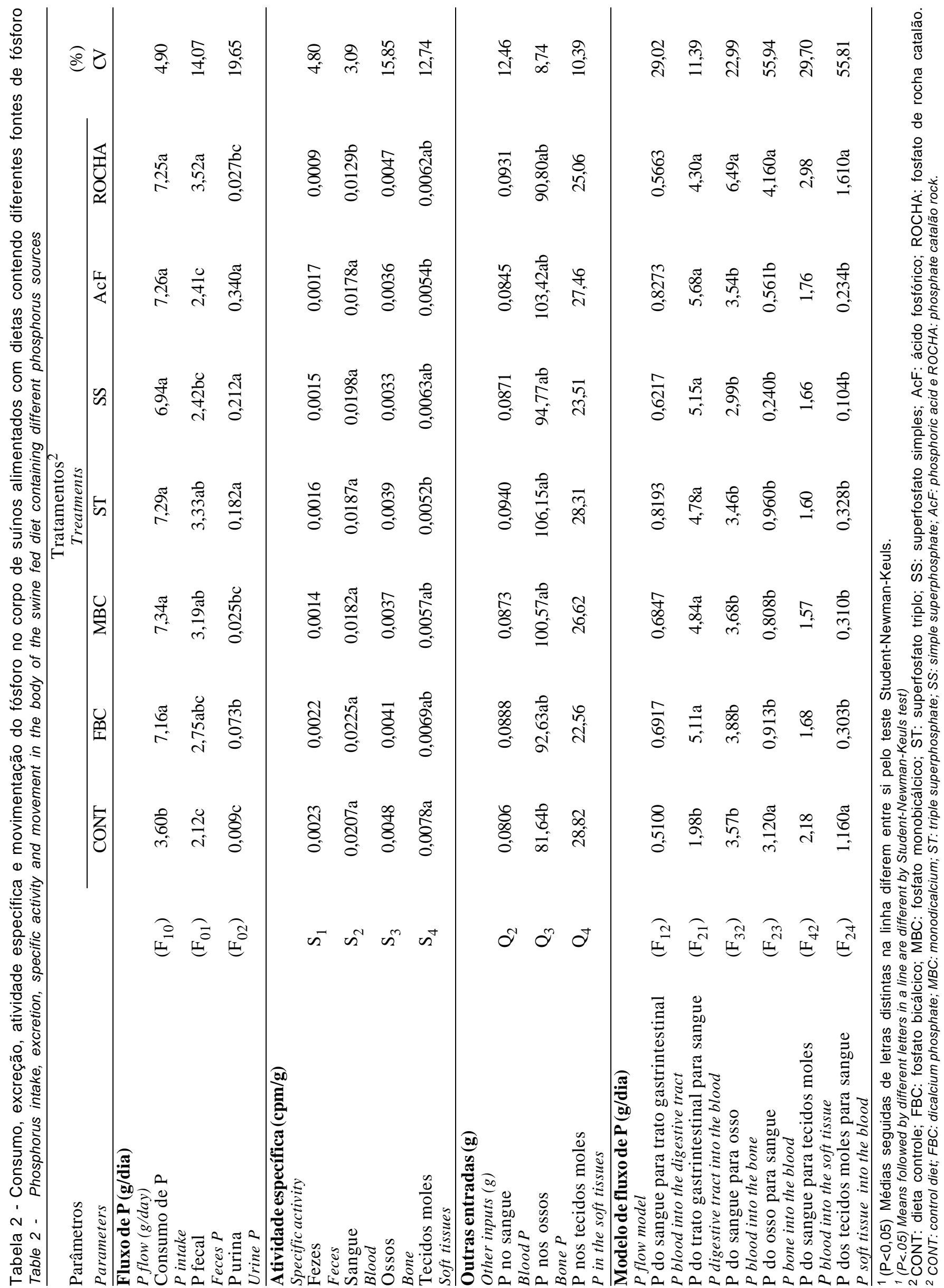


pela fonte de $\mathrm{P}$ da dieta. No entanto, o mesmo não foi observado para fluxo do trato digestivo para a corrente sangüínea $\left(\mathrm{F}_{21}\right)$ : os animais que consumiram a dieta CONT tiveram menor $(\mathrm{P}<0,05)$ fluxo, não havendo diferença $(P>0,05)$ entre os animais que receberam os demais tratamentos.

O P incorporado $\left(\mathrm{F}_{32}\right)$ e o reabsorvido dos ossos $\left(\mathrm{F}_{23}\right)$ foram influenciados $(\mathrm{P}<0,05)$ pela fonte de fósforo. Animais que consumiram dieta contendo fosfato de rocha apresentaram maior fluxo de P do sangue para o osso. Contudo, os animais submetidos aos tratamentos ROCHA e CONT reabsorveram mais $\mathrm{P}$ do osso que os dos demais tratamentos.

A mobilização de $\mathrm{P}$ da corrente sangüínea para os tecidos moles $\left(\mathrm{F}_{42}\right)$ não foi influenciada $(\mathrm{P}>0,05)$ pela fonte de fósforo. Entretanto, a mobilização dos tecidos moles para a corrente sangüínea $\left(\mathrm{F}_{24}\right)$ foi maior $(\mathrm{P}<0,05)$ nos animais que consumiram dieta contendo ROCHA e CONT.

A maior mobilização de $\mathrm{P}$ do osso para a corrente sanguiínea $\left(\mathrm{F}_{23}\right)$ pode estar relacionada à baixa biodisponibilidade de $\mathrm{P}$ nos tratamentos que contêm baixo nível deste mineral e naqueles suplementados com fosfato de rocha, que possuem baixa disponibilidade e, portanto, não são capazes de atender às exigências nutricionais do organismo. Esse fluxo entre os compartimentos parece tratar-se de mecanismo para manter estável o nível de $\mathrm{P}$ no plasma. O aumento da saída dos tecidos moles $\left(\mathrm{F}_{24}\right)$ nestes tratamentos também contribui para manutenção dos níveis de $\mathrm{P}$ na corrente sangüínea e para o desempenho das funções normais no organismo animal.

Para o P inorgânico no osso, verificou-se que houve mudança em função da fonte de fósforo consumido, como está caracterizado nos resultados da atividade específica nesse compartimento. Esses resultados divergem daqueles de Fernandez (1995b) e Lopes (1999), que constataram que a incorporação de $\mathrm{P}$ no osso foi constante, independentemente do nível de ingestão, porém estão em consonância quanto à reabsorção óssea, uma vez que Fernandez (1995b) verificou que a reabsorção decresceu com o aumento da ingestão de $\mathrm{P}$; Lopes (1999), entretanto, não verificou esse efeito.

Aumento da excreção de $\mathrm{P}$ na urina para o tratamento contendo ácido fosfórico, que possui alta disponibilidade, indica que, nos monogástricos, os rins constituem importante rota para a homeostase de $\mathrm{P}$, ao lado da excreção fecal (Cupák et al., 1972; Vippermam JR. et al., 1974; Georgievskii, 1982; Breves \& Schröder, 1991; Fernandez, 1995a,b; Lopes,
1999). As perdas urinárias de $\mathrm{P}$ em suínos podem estar diretamente relacionadas ao maior valor da eficiência de absorção, quando a concentração de P no plasma excede o limiar renal.

No desenvolvimento do modelo, constatou-se que alguns animais apresentaram valor negativo para o $\mathrm{P}$ reabsorvido dos ossos e tecidos moles. Isso sugere que não houve saída de $\mathrm{P}$ desse compartimento para a corrente sangüínea, ficando, assim, o P incorporado aos ossos e tecidos moles. Essa ocorrência pode estar relacionada, em parte, com a maior eficiência de absorção do $\mathrm{P}$ nestes animais, permitindo que o $\mathrm{P}$ fique mobilizado no osso e nos tecidos moles, para utilização posterior, quando houver carência ou problemas metabólicos no organismo.

\section{Conclusões}

A utilização de fonte orgânica de fósforo e fosfato de rocha não forneceu fósforo suficiente para suprir as exigências nutricionais dos suínos, sendo o fluxo do fósforo dos tecidos moles e dos ossos mais intenso, para estabilidade de $\mathrm{P}$ na corrente sangüínea. A utilização de ácido fosfórico e superfosfato simples nas dietas sobrecarregou os rins, na eliminação do excedente de $\mathrm{P}$ pela urina.

\section{Literatura Citada}

BASTIANELLI, D.; SAUVANT, D.; RÉRAT, A. Mathematical modeling of digestion and nutrient absorption in pig. Journal of Animal Science, v.74, n.10, p.1873-1887, 1996.

BREVES, G.; SCHRÖDER, B. Comparative aspects of gastrointestinal phosphorus metabolism. Nutrition Research Reviews, v.4, p.125-140, 1991.

CUPÁK, M.; PROCHAZKA, Z.; JAMBOR, V. Utilization of phosphorus compounds in pigs after endogenous phosphorus determination means of ${ }^{32} \mathrm{P}$. Acta Veterinaria Brno, v.41, p.257-262, 1972.

FERNANDEZ, J.A. Calcium and phosphorus metabolism in growing pigs. I. Absorption and balance studies. Livestock Production Science, v.41, n.1, p.233-241, 1995a.

FERNANDEZ, J.A. Calcium and phosphorus metabolism in growing pigs. II. Simultaneous radio-calcium and radiophosphorus kinetics. Livestock Production Science, v.41, n.1, p.243-254, 1995b.

FIGUEIRÊDO, A.V.; VITTI, D.M.S.S.; LOPES, J.B. Cinética do radiofósforo em tecidos de suínos em crescimento, alimentados com dietas contendo diferentes fontes fosfatadas. In: REUNIÃO ANUAL DA SOCIEDADE BRASILEIRA DE ZOOTECNIA, 35., 1998, Botucatu. Anais... Botucatu: Sociedade Brasileira de Zootecnia, 1998. p.207-209.

FISKE, C.H.; SUBBARROW, Y. The calorimetric determination of phosphorus. Journal Biological Chemistry, v.66, n.2, p.375-400, 1925. 
FURTADO, M.A.O. Determinação da biodisponibilidade de fósforo em suplementos de fósforo para aves e suínos. Belo Horizonte: Universidade Federal de Minas Gerais, 1991. 60p. Dissertação (Mestrado em Zootecnia) Universidade Federal de Minas Gerais, 1991.

GEORGIEVSKII, V.I. The phisiological role of macroelements. In: GEORGIEVSKII, V.I.; ANNENKOV, B.N.; SAMOKHIN, V.I. (Eds.) Mineral nutrition of animals. 1.ed. London: Butterworths, 1982. p.91-170.

INTERNATIONAL ATOMIC ENERGY AGENCY - IAEA. Laboratory training manual on the use of nuclear techniques in animal research. Vienna: IAEA, 1979, 299p. (Technical Report Series, 193), 1979.

LOPES, J.B. Cinética e metabolismo do fósforo em ruminantes e não ruminantes: modelos matemáticos. Piracicaba: Universidade de São Paulo, 1999. 84p. Relatório (Pós-Doutorado) - Centro de Energia Nuclear na Agricultura - Universidade de São Paulo.

LOPES, J.B.; VITTI, D.M.S.S.; ABDALLA, A.L. Modelo do fluxo biológico do fósforo de fontes de fosfato em suínos, usando o ${ }^{32} \mathrm{P}$ como marcador. Revista Brasileira de Zootecnia, v.30, n.1, p.165-173, 2001.

PEKAS, J.C. Versatile swine laboratory apparatus for physiologic and metabolic studies. Journal of Animal Science, v.27, n.5, p.1303-1306, 1968.
ROSTAGNO, H.S.; ALBINO, L.F.T.; DONZELE, J.L. et al. Tabelas brasileira para aves e suínos: composição de alimentos e exigências nutricionais. Viçosa, MG: Universidade Federal de Viçosa, 2000. p.141.

SALVIANO, L.M.C.; VITTI, D.M.S.S. Effect of dietary Ca:P ratio on endogenous fecal losses and on $\mathrm{P}$ absorption in seep. Pesquisa Agropecuária Brasileira, n.33, p.349-355, 1998.

SARRUGE, J.R.; HAAG, H.P. Análises químicas em plantas. Piracicaba: Universidade de São Paulo, 56p. 1974.

STATISTICAL ANALYSES SYSTEM - SAS. SAS System for Windows, release 6.12 Cary: 1996 (01 CD-ROM).

VIPPERMAN JR., P.E.; PEO JR., E.R.; CUNNINGHAM, P.J. Effect of dietary calcium and phosphorus level upon calium, phosphorus and nitrogen balance in swine. Journal of Animal Science, v.38, n.4, p.758-765, 1974.

VITTI, D.M.S.S.; KEBREAB, E.; LOPES, J.B. et al. A kinetic model of phosphorus metabolism in growing goats. Journal of Animal Science, v.78, p.2706-2712, 2000.

Recebido em: 22/04/03

Aceito em: 01/12/03 